\title{
BMJ open Inattention and hyperactivity in children at risk of obesity: a community cross-sectional study
}

\author{
Lorna McWilliams, Kapil Sayal, Cris Glazebrook
}

To cite: McWilliams L, Sayal K, Glazebrook C. Inattention and hyperactivity in children at risk of obesity: a community cross-sectional study. BMJ Open 2013;3: e002871. doi:10.1136/ bmjopen-2013-002871

- Prepublication history for this paper is available online. To view these files please visit the journal online (http://dx.doi.org/10.1136/ bmjopen-2013-002871).

Received 12 March 2013 Revised 17 April 2013 Accepted 19 April 2013

This final article is available for use under the terms of the Creative Commons Attribution Non-Commercial 2.0 Licence; see http://bmjopen.bmj.com

Division of Psychiatry, Institute of Mental Health, University of Nottingham, Nottingham, UK

Correspondence to Lorna McWilliams; mcxIm@nottingham.ac.uk

\begin{abstract}
Objective: There is a link between the symptoms of hyperactivity/inattention and overweight in children. Less is known about the factors which might influence this relationship, such as physical and sedentary activity levels or exercise self-efficacy. The aim of this study is to examine the associations between the symptoms of hyperactivity/inattention and risk factors for adult obesity in a sample of children with barriers to exercise.
\end{abstract}

Design: Children aged 9-11 years were recruited from 24 primary schools that participated in the Steps to Active Kids (STAK) physical activity intervention study. Study inclusion criteria were low exercise self-efficacy, teacher-rated overweight or asthma. Children with high levels of physical activity were excluded. Measures included parent and teacher-rated behavioural and emotional well-being using the Strengths and Difficulties Questionnaire, physical and sedentary activity levels, BMI (body mass index) and exercise self-efficacy.

Results: Of 424 participating children, $62 \%$ were girls and $39 \%$ were classified as overweight or obese. As compared with population norms, boys in this at-risk sample were more likely to receive an abnormal teacher-rated hyperactivity/inattention score (OR 1.48, $95 \% \mathrm{Cl} 1.01$ to 2.17). Children with teacher-rated abnormal hyperactivity/inattention scores reported higher levels of sedentary activity (OR $1.13,95 \% \mathrm{Cl}$ 1.02 to 1.17 ), but not physically active activity. The pattern of findings was similar for children with hyperactivity/inattention problems as rated by both parent and teacher (pervasive hyperactivity and impairment).

Conclusions: Although BMI was not directly related to hyperactivity/inattention, children with risk factors for adult obesity have more hyperactivity/inattention problems. In particular, hyperactivity/inattention is associated with higher levels of sedentary activity. Higher rates of pervasive hyperactivity and impairment were apparent in this at-risk group.

\section{INTRODUCTION}

There is longitudinal evidence that poor physical fitness and inactivity in childhood increases the risk of obesity in adulthood. ${ }^{1-3}$

\section{ARTICLE SUMMARY}

Article focus

- Increased sedentary activity and decreased physical activity levels are known risk factors for the development of obesity.

- There is a relationship between hyperactivity/ inattention and obesity in childhood. This relationship may be underpinned by associated difficulties with coordination or self-regulation.

- This study assessed whether children with risk factors for adult obesity, including current overweight and low levels of physical activity, were also likely to score above cut-off for inattention and hyperactivity.

\section{Key messages}

- Sedentary children with risk factors for obesity have an increased risk of hyperactivity/ inattention.

- Interventions to promote physical activity in sedentary or overweight children need to accommodate potential difficulties with inattention and hyperactivity.

Strengths and limitations of this study

- The study used a well-validated measure of inattention and hyperactivity with multiple informants (teacher and parent).

- This study used normative data to establish increased risk of attention deficit hyperactivity disorder symptoms rather than a contemporary comparison group of physically active children.

Research in Western countries has highlighted that childhood health problems associated with being overweight and physically inactive are known risk factors for predicting overweight and associated health problems in adulthood. ${ }^{45}$ Early intervention for children with barriers to exercise such as low exercise self-efficacy (confidence about participation in exercise) or chronic health conditions, for example, asthma, is therefore important to aim to reduce the risk of obesity later in life. There is some evidence that children with chronic conditions have higher rates of obesity and lower physical activity levels. ${ }^{6}$ The 
neurodevelopmental disorder, attention deficit hyperactivity disorder (ADHD), is one of the most common childhood disorders with a world-wide prevalence rate of around $3-5 \%$ and long-term adverse consequences. ${ }^{7}$ Sub-threshold high levels of hyperactivity/inattention, particularly when pervasive across settings, are also a risk factor for later problems. ${ }^{8}$ Although symptoms of hyperactivity/inattention might be expected to reduce the risk of obesity due to the increased metabolism of calories through increased customary activity levels, growing evidence suggests an association between weight problems and symptoms of ADHD, possibly due to difficulties with self-regulation. ${ }^{910}$

Several studies have demonstrated this relationship within clinically obese or clinically diagnosed ADHD samples $^{11} 12$ and in population-based studies. ${ }^{13}{ }^{14}$ However, the findings are inconsistent possibly because of cross-sectional designs, methodological and sample characteristic differences. ${ }^{15-17}$ Some children with ADHD may have low self-esteem and social functioning problems as well as possible coordination difficulties. ${ }^{18} 19$ These problems may influence self-confidence and participation in physical activity, referred to as exercise selfefficacy and could therefore become risk factors for the development of later obesity. Despite this, many studies which investigate the relationship between weight and hyperactivity/inattention problems do not explore factors that might influence this relationship such as physical or sedentary activity levels and exercise selfefficacy. To date, no research has looked at both weight and symptoms of hyperactivity/inattention in children with barriers to exercise and who are at risk for adult obesity. Studies including sedentary or physical activity measures have either not looked at hyperactivity/ inattention or have used non-standardised measures to assess activity levels and child behaviour. ${ }^{20-22}$ Some studies report gender differences in the relationship between behaviour, including hyperactivity/inattention, and weight; however, these studies have involved samples of younger children. ${ }^{23-25}$ It is important to establish whether hyperactive/inattentive children are overrepresented in at-risk groups since they may be less likely to be targeted for activity interventions as many of these target physical health outcomes. ${ }^{26}$

The aims of this study are to explore rates of inattention and hyperactivity in a sample of children with barriers to physical activity and to explore which risk factors for adult obesity are associated with symptoms of hyperactivity/inattention. We hypothesised that children with risk factors for adult obesity (current overweight or barriers to physical activity) will have high rates of difficulties with hyperactivity and inattention.

\section{METHODS}

Participants

This study uses screening baseline data from a cluster randomised controlled trial collected April 2010-November
2011, the Steps to Active Kids (STAK) study. ${ }^{27}$ STAK is assessing the impact of a targeted physical activity intervention in children aged 9-11 years with risk factors for adult obesity. ${ }^{27}$ Twenty-four schools agreed to participate and an opt-out procedure was used to screen children in years 5 and 6 of primary school (see figure 1). Parents received a letter with information about the screening process and study. Of the 2479 children who were screened, 1065 met the eligibility criteria and were invited to take part prior to randomisation. ${ }^{27}$ Children with high levels of customary physical activity were excluded as the STAK intervention is specifically designed to meet the needs of children with low levels of exercise self-efficacy.

\section{Measures}

Screening

For each child, their class teacher completed screening questions to identify those with risk factors for adult obesity. Children reported whether they had a diagnosis of asthma, participated in team sports and had an active hobby and how often they participated in the activity. They completed the nine-item predilection subscale of the Children's Self-Perceptions of Adequacy in and Predilection for Physical Activity (CSAPPA) to assess willingness to engage in physical activity with a cut-off of 27 or below indicating low-exercise self-efficacy. ${ }^{28}$ Teachers rated the child's build using the Child Body Image Scale, which represents centile bands according to the 1990 growth charts. ${ }^{29}{ }^{30}$ Teachers also answered whether children found physical education (PE) difficult due to asthma, overweight, coordination problems or lack of fitness as well as whether the child was sporty.

Inclusion criteria for the main STAK study comprised of one or more of the following: child-rated asthma, child-rated low exercise self-efficacy, teacher-rated build at above 85th centile and teacher-rated concern about participation in PE. If the children participated regularly in an active hobby or a team sport and were rated as 'sporty' by their teacher, they were excluded.

\section{Baseline study measures}

Child symptoms of hyperactivity/inattention were assessed using both the teacher-rated and parent-rated

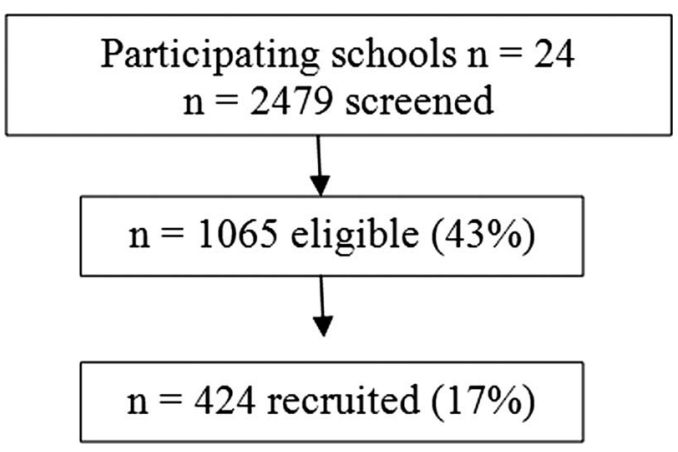

Figure 1 Screening of participants and recruitment flow. 
Strengths and Difficulties Questionnaire (SDQ). ${ }^{31}$ The SDQ is a widely used measure to assess emotional and behaviour difficulties in children aged 4-16 years. The questionnaire contains five subscales (prosocial, emotional, conduct, peer problems and hyperactivity/ inattention) and provides a total score incorporating the latter four subscales. Subscale scores range from 0 to 10 with the total score ranging from 0 to 40 . There is also an impact score, which indicates the level of child distress and associated social impairment. There are abnormal cut-off scores for both totals and subscales, with a score of 7 or above indicating hyperactivity/inattention problems which has been found to have $74-75 \%$ sensitivity at predicting a Diagnostic and Statistical Manual of Mental Disorders, Fourth Edition (DSM-IV) diagnosis of ADHD. ${ }^{32}$ In addition, 'probable ADHD' reflects those children rated as having both parent-rated and teacherrated scores of 6 or above for hyperactivity/inattention (pervasive hyperactivity) and impact scores of 1 or above (impairment) ${ }^{31}{ }^{33}$ Although children with pervasive hyperactivity and impairment may not all meet criteria for a clinical diagnosis, this algorithm reflects the use of multiple informants to determine that symptoms and impact are pervasive across settings, thus compares well with a diagnostic interview. ${ }^{34}$ The SDQ has high validity and reliability and has been shown to discriminate between children who have received a clinical diagnosis of ADHD and those who have not. ${ }^{35}$

Height was measured using a stadiometer and weight was recorded where each child removed any extra clothing (eg, sweater) and footwear for both measurements which were each recorded once. Waist circumference was recorded using a tape equidistant between the iliac crest and the base of the rib cage; the children were asked to breathe as normal. Body mass index (BMI) centiles were calculated in weight/height ${ }^{2}$ using the British 1990 growth reference chart for children adjusting for age and gender. ${ }^{36}$ Participants with a centile of 91-96 were classified as overweight and those with a centile of 97 or above as obese. ${ }^{36}$ Children were asked whether they had a diagnosis of asthma.

Exercise self-efficacy was assessed using the CSAPPA Scale. ${ }^{28}$ This measure has been developed and validated for use in 8 to 16-year-old children and adolescents to examine self-report attitudes towards physical activity participation. The three subscales measure adequacy (self-confidence), predilection (preference for) and enjoyment of physical activity, with higher scores indicating higher exercise self-efficacy. It has been found to moderately relate to performance on aerobic fitness as well as self-reported physical activity participation. ${ }^{37} 38$

Self-report sedentary and physical activity levels were measured using a UK modified version of the Physical Activity Questionnaire (PAQ) ${ }^{39}$ The modified version has been used in previous studies and contains 59 items including physical activity (eg, running) and sedentary activity (eg, television viewing) ${ }^{6}$ Children rate their participation in each activity (none, a little and a lot) in three time periods within the previous $24 \mathrm{~h}$ (before school today, after school yesterday and during school yesterday). Higher physical activity scores indicate higher levels of participation in physical activity, while higher sedentary activity scores indicate higher levels of participation in sedentary activity.

\section{Statistical analysis}

Data were analysed using SPSS V.17.0. Teacher ratings of child behaviour were compared with the UK normative data $^{40}$ (boys, $n=4073$ and girls, $n=4135$; aged $5-15$ years) to calculate the ORs separately for boys and girls. Non-parametric analyses were conducted as appropriate. Participant characteristics were assessed for gender differences using Mann-Whitney $U$ tests. Scores from the teacher-rated hyperactivity/inattention subscale were treated as categorical as we were specifically interested in children with high (high hyperactivity/inattention group) and low (low hyperactivity/inattention group) scores in relation to risk factors for adult obesity. Comparisons between children with teacher-rated abnormal hyperactivity/inattention scores (score of 7 or above) and those with low scores on risk factors for adult obesity (BMI centile, physical and sedentary activity levels and exercise self-efficacy) were made using Mann-Whitney U tests. Associations between abnormal teacher-rated hyperactivity/inattention scores and risk factors for adult obesity were assessed using logistic regression analyses for the whole sample. Adjustments were made for the possible influence of gender (categorial) plus other teacher-rated SDQ subscales (conduct, peer problems, prosocial and emotional), BMI centile, physical activity levels, sedentary activity levels and exercise self-efficacy (all continuous). Comparisons between those rated with and without pervasive hyperactivity and impairment $(6+$ cut-off scores for both parent-rated and teacher-rated hyperactivity/ inattention and impact of $1+$ for both parent and teacher) were assessed using Mann-Whitney U tests separately by gender due to differences in this subsample.

\section{Ethical approval}

Approval for this study was received from the University of Nottingham Medical School Ethics Committee.

\section{RESULTS}

After screening, the parental consent for participation was received for $424(40 \%)$ children who met the eligibility criteria. Based on screening data, participants and non-participants did not differ in relation to gender, exercise self-efficacy or teacher-rated overweight. Among the participating sample, $62 \%$ were girls and $13 \%$ selfreported asthma (table 1). Thirty-nine per cent were classified as overweight or obese. ${ }^{36}$ Information on child behaviour was received for $371(87.5 \%)$ children through the teacher-rated SDQ. Both parent and teacher-rated SDQ information was received for 270 
Table 1 Participants' demographic information

\begin{tabular}{|c|c|c|c|}
\hline & $\begin{array}{l}\text { Boys }(n=161) \\
\text { Median (IQR) }\end{array}$ & $\begin{array}{l}\text { Girls }(n=263) \\
\text { Median (IQR) }\end{array}$ & $\begin{array}{l}\text { U } \\
\text { p Value }\end{array}$ \\
\hline Age (years) & $10(9-10)$ & $10(9-10)$ & 0.60 \\
\hline Weight (kg) & $38.1(32-48)$ & $38.6(32-48)$ & 0.90 \\
\hline Height (cm) & $142(137-147)$ & $142(136-146)$ & 0.85 \\
\hline Waist $(\mathrm{cm})$ & $70(63-81)$ & $68(61-77)$ & 0.08 \\
\hline Body Mass Index centile & $88(48-98)$ & $79(44-96)$ & 0.05 \\
\hline Active score (PAQ) & $57(50-67)$ & $59(52-66)$ & 0.51 \\
\hline Sedentary score (PAQ) & $25(22-29)$ & $25(22-29)$ & 0.88 \\
\hline CSAPPA total & $53(46-60)$ & $50(43-57)$ & 0.04 \\
\hline SDQ teacher total score (out of 40 ) & $10(6-17)$ & $5(2-11)$ & $<0.001^{\star *}$ \\
\hline $\begin{array}{l}\text { SDQ teacher hyperactivity/inattention subscale } \\
\text { (out of } 10, \geq 7 \text { abnormal cut-off) }\end{array}$ & $4(2-7)$ & $2(0-4)$ & $<0.001^{\star *}$ \\
\hline
\end{tabular}

(64\%) children. There were no statistically significant differences between the children who did and did not have both parent-completed and teacher-completed SDQ information in relation to age, gender, activity levels, exercise self-efficacy and weight.

\section{Comparisons on teacher-rated hyperactivity/inattention} between study sample and normative data

Boys in the study were almost 1.5 times more likely $(\mathrm{p}<0.05)$ to have high hyperactivity/inattention scores compared with the normative sample (table 2). They were also more likely to have scores in the abnormal range across all SDQ domains compared with population norms. Table 2 also shows that both boys and girls were around twice as likely to have total SDQ scores in the abnormal range compared with population norms.
Comparisons between high and low teacher-rated hyperactivity/inattention and risk factors for adult obesity For boys and girls combined, children with abnormal teacher-rated hyperactivity/inattention scores had higher levels of sedentary activity (median, Mdn=28) than children with low scores $(\mathrm{Mdn}=25, \mathrm{U}=5939$; $\mathrm{p}<0.001)$. No other differences in risk factors for obesity (BMI centile, exercise-self efficacy or physical activity) were found between those with high and low hyperactivity/ inattention (table 2).

Teachers rated more boys with abnormal hyperactivity inattention scores $\left(\chi^{2}(1)=19.77, \mathrm{p}<0.001\right)$; therefore, analyses were also conducted separately by gender (table 3 ). Boys and girls with abnormal teacher-rated hyperactivity/ inattention scores reported higher levels of sedentary activity $(\mathrm{Mdn}=28, \mathrm{p}=0.01$ and 29; $\mathrm{p}<0.001$, respectively). Girls with abnormal teacher-rated hyperactivity/inattention

Table 2 Teacher-rated SDQ total and subscale abnormal scores comparing the study sample with normative data

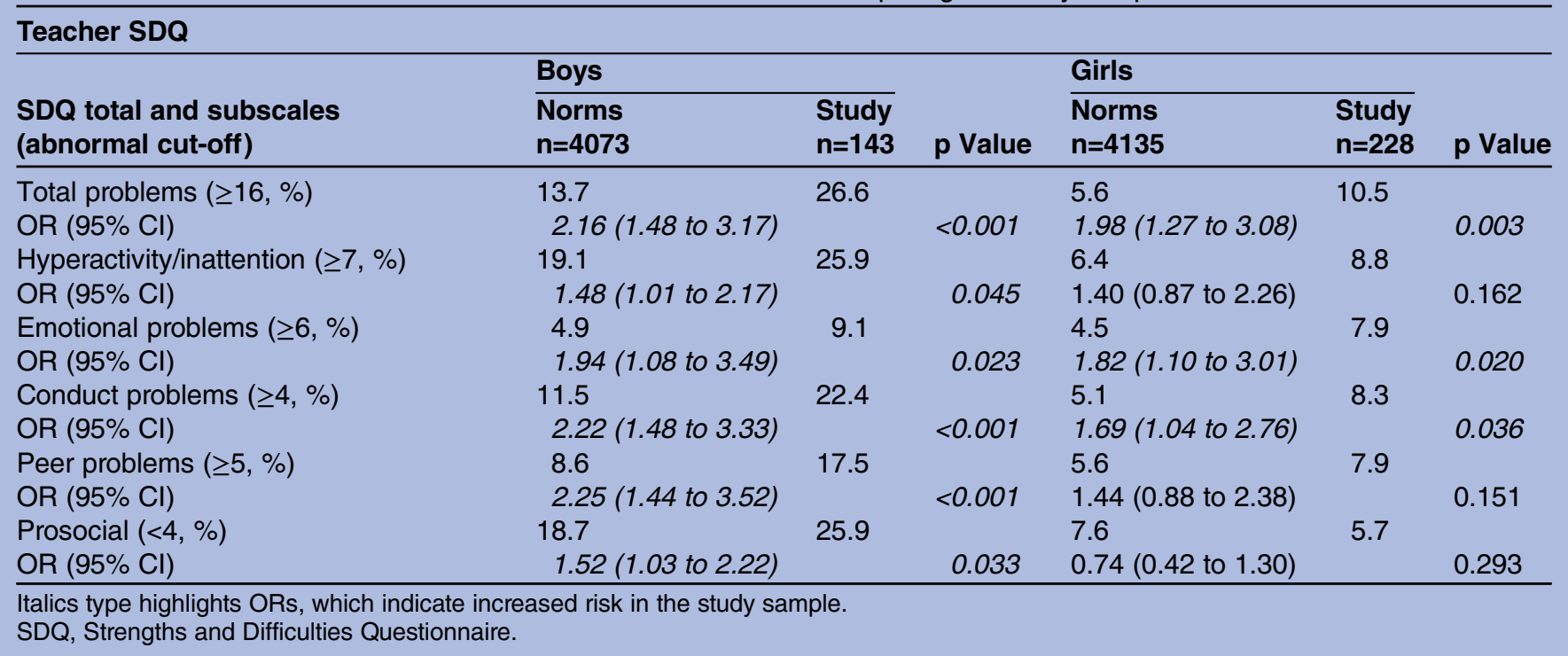


Table 3 Comparisons between high and low teacher-rated SDQ hyperactivity/inattention scores

\begin{tabular}{|c|c|c|c|c|c|c|c|c|c|}
\hline & \multicolumn{3}{|l|}{ Boys } & \multicolumn{3}{|l|}{ Girls } & \multicolumn{3}{|l|}{ Whole } \\
\hline & $\begin{array}{l}\text { High } \\
\text { Median (IQR) }\end{array}$ & Low & $\begin{array}{l}\text { U } \\
\text { p Value }\end{array}$ & $\begin{array}{l}\text { High } \\
\text { Median (IQR) }\end{array}$ & Low & $\begin{array}{l}U \\
p \text { Value }\end{array}$ & $\begin{array}{l}\text { High } \\
\text { Median (IQR) }\end{array}$ & Low & $\begin{array}{l}\text { U } \\
\text { p Value }\end{array}$ \\
\hline BMI centile & 87 (47-98) & 89 (47-99) & 0.36 & 84 (55-99) & $82(43-96)$ & 0.28 & 87 (51-98) & $85(45-97)$ & 0.70 \\
\hline Active score (PAQ) & $58(49-68)$ & 55 (49-65) & 0.31 & $64(58-67)$ & $57(51-65)$ & 0.22 & $61(52-67)$ & 57 (50-65) & 0.10 \\
\hline Sed score (PAQ) & $28(24-31)$ & $24(22-28)$ & $0.01^{*}$ & 29 (27-35) & $25(22-28)$ & $0.04^{*}$ & $28(25-33)$ & 25 (22-28) & $<0.001^{* *}$ \\
\hline CSAPPA total & $52(39-60)$ & $54(48-60)$ & 0.26 & $55(48-60)$ & $50(43-58)$ & $<0.001^{\star *}$ & $53(42-60)$ & $52(44-59)$ & 0.81 \\
\hline
\end{tabular}

${ }^{*} \mathrm{p}<0.05$.

${ }^{* *} \mathrm{p}<0.001$.

BMI, Body Mass Index; CSAPPA, Children's Self-Perceptions of Adequacy in and Predilection for Physical Activity Scale; High, high hyperactivity/inattention score $\geq 7$; IQR, interquartile range;

Low, low hyperactivity/inattention score <7; PAQ, Physical Activity Questionnaire; SDQ, Strengths and Difficulties Questionnaire; Sed, sedentary activity; U, Mann-Whitney U test.

Table 4 Characteristics of pervasive hyperactivity subsample

\begin{tabular}{|c|c|c|c|c|c|c|}
\hline & $\begin{array}{l}\text { No PH boys } \\
\text { Median (IQR) }\end{array}$ & PH boys & $\begin{array}{l}\text { U } \\
\text { p Value }\end{array}$ & $\begin{array}{l}\text { No PH girls } \\
\text { Median (IQR) }\end{array}$ & PH girls & $\begin{array}{l}\text { U } \\
\text { p Value }\end{array}$ \\
\hline Age (years) & $10(9-10)$ & $9.5(9-10)$ & 0.45 & $10(9-10)$ & $10(9-10)$ & 0.62 \\
\hline Weight (kg) & $40(33-49)$ & $35.08(30-49)$ & 0.18 & $39.65(32-47)$ & $38.2(33-51)$ & 0.93 \\
\hline Height (cm) & $141.8(138-147)$ & 141.95 (135-147) & 0.70 & $141.5(136-146)$ & $142(138-147)$ & 0.87 \\
\hline Waist (cm) & $71.5(63-82)$ & $64(61-79)$ & 0.12 & $69(62-76)$ & $67(61-80)$ & 0.91 \\
\hline BMI centile & 90 (59-99) & $62(34-98)$ & 0.14 & $82(48-97)$ & $80(68-96)$ & 0.76 \\
\hline Active score (PAQ) & $56(49-65)$ & $55(47-67)$ & 0.82 & $57(51-64)$ & $64(47-68)$ & 0.36 \\
\hline Sedentary score (PAQ) & $24(22-28)$ & 26 (22-29) & 0.45 & $24(22-28)$ & $29(24-36)$ & $0.06^{*}$ \\
\hline CSAPPA total & $55(48-63)$ & $50(39-57)$ & 0.07 & $50(43-57)$ & $49(35-57)$ & 0.59 \\
\hline
\end{tabular}

\section{${ }^{*} p<0.05$}

BMI, Body Mass Index; CSAPPA, Children's Self-Perceptions of Adequacy in and Predilection for Physical Activity Scale; IQR, interquartile range; PAQ, Physical Activity Questionnaire;

$\mathrm{PH}$, pervasive hyperactivity score of $\geq 6$ by parent and teacher on hyperactivity/inattention SDQ subscale and impact score of $\geq 1$; SDQ, Strengths and Difficulties Questionnaire;

$\mathrm{U}$, Mann-Whitney U test. 
scores also reported higher levels of physical activity (Mdn $=63.5, \mathrm{p}=0.039$ ). No other gender differences were found on the other risk factors for obesity (BMI centile and exercise self-efficacy) between high and low hyperactivity/ inattention.

The logistic regression analyses confirmed that children with abnormal teacher-rated scores for hyperactivity/inattention were four times more likely to be boys (OR $4.10,95 \%$ CI 2.14 to $7.76 ; \mathrm{p}<0.001$ ) and have an increased risk of participating in more sedentary activities (OR 1.13, 95\% CI 1.05 to $1.21 ; \mathrm{p}<0.001$ ) than children with sub-threshold scores. Participation in sedentary activities remained significant $(p=0.01)$ when adjusting for other SDQ subscales (emotion, peer problems, conduct and prosocial). Other factors such as exercise self-efficacy, age, BMI centile and physical activity levels were not associated with abnormal hyperactivity/inattention scores.

\section{Pervasive hyperactivity and impairment in children with risk factors for obesity and barriers to exercise}

Thirty-one $(11.5 \%)$ children were classified with pervasive hyperactivity and impairment $(64.5 \%$ boys; table 4$)$. There was a significantly higher number of boys than girls classified $\left(\chi^{2}=9.68, \mathrm{p}=0.002\right)$. In girls, the levels of sedentary activity differed between those with pervasive hyperactivity and those without. Girls with pervasive hyperactivity and impairment reported higher levels of sedentary activity participation $(\mathrm{p}=0.05)$. No other differences between the groups were found relating to physical activity levels and exercise self-efficacy.

\section{DISCUSSION}

This study found high rates of hyperactivity/inattention problems in boys in this sample of children with risk factors for physical inactivity and adult overweight. Children with high teacher-rated hyperactivity/inattention scores had higher reported levels of sedentary activity than those with low scores. This finding remained significant after adjusting for confounders. For girls, higher teacher-rated hyperactivity/inattention was also associated with higher reported physical activity levels. We found no evidence that weight was associated with hyperactivity/inattention in this selected at-risk sample.

Our finding of higher rates of hyperactivity/inattention in boys in this at-risk sample concords with higher rates of ADHD in boys in the general population. ${ }^{8}$ Furthermore, our rate of pervasive hyperactivity and impairment was markedly higher $(11.5 \%)$ than that found in another school-based community study (3-4\%) despite there being a larger proportion of girls in our sample. ${ }^{41}$ We did not find an association between weight and symptoms of ADHD similar to previous studies using clinical and community-based samples. ${ }^{42}{ }^{43}$ Ebenegger $e t a l^{44}$ also used the hyperactivity/inattention SDQ subscale and found that although symptoms of ADHD were not related to BMI, children with hyperactive/inattentive symptoms participated in increased physical activity and television viewing. We demonstrated that children with high teacher-rated hyperactivity/inattention scores reported higher sedentary activity levels. This finding is supported by previous research, which illustrated that sedentary activity such as television viewing and video game playing were related to attention problems. ${ }^{45-47}$ Our findings suggest that although children with hyperactivity/inattention, in this selected sample, do not have lower levels of physical activity compared with those with symptoms of hyperactivity/inattention in the normal range, they do report more sedentary activity participation. This supports findings from a recent study of a large community sample of children aged 6-17 years which found that compared with children without ADHD, children with unmedicated ADHD were more likely to be rated as inactive. ${ }^{22}$ Girls with unmedicated ADHD had higher levels of TV and computer use. This is particularly important given that children generally are spending increased time participating in sedentary activities and less time engaging in physical activity. ${ }^{48}$ Furthermore, there is evidence that children in this age group with lower levels of fitness are associated with higher teacher-rated scores for hyperactivity/inattention. ${ }^{25}$ Our finding of increased sedentary activity in the pervasive hyperactivity and impairment subsample supports the findings using only the teacher-rated SDQ as a measure of hyperactivity/ inattention problems. This subscale only has five items assessing hyperactivity/inattention limiting the ability to analyse the different components of ADHD separately, but remains a useful screening tool. Furthermore, the mean exercise self-efficacy score for the pervasive hyperactivity and impairment group was markedly lower than the cut-off for concern considered to indicate low levels of confidence by the researchers who developed the measure. ${ }^{28}$ Our findings lend support to the importance of identifying at-risk children for interventions.

We found that girls reported higher physical activity levels which is similar to that found in Baerg et $a l^{49}$ Baerg et al found that boys with ADHD and developmental coordination disorder, one of our teacher screening questions, had lower levels of physical activity, but girls had higher levels. It is not clear whether higher reported physical activity indicates higher energy expenditure, particularly as there were no differences in weight between those with high and low hyperactivity/ inattention scores, with both groups having high rates of obesity in this sample of children selected for risk factors for adult obesity. ${ }^{50}$ As this sample was selected as having low exercise self-efficacy and low participation in physical activity, further research is needed to compare those with high and low levels of exercise self-efficacy or high and low levels of physical activity participation to help clarify the findings.

This study was cross-sectional in nature and lacked a control group limiting the ability to identify the direction of the effect between activity levels and hyperactivity/ 
inattention or to explain the mechanisms underlying this relationship. Longitudinal studies are required to explore the development of activity levels, behavioural symptoms, risk factors for obesity over time and comparisons of those with high and low symptoms of hyperactivity/ inattention or high and low physical activity levels. This would help establish how children rated with hyperactivity/inattention problems are represented in terms of high and low physical activity participation. Although the age range of our study sample was narrow, it reflects the current high levels of obesity reported in this age group and is an important age for targeted interventions before the transfer to secondary schools and adolescent development. ${ }^{50}$ The use of a subjective measure of activity levels should be treated with caution due to possible report bias; further work could include objective measures such as accelerometers alongside self-report activity levels. Given that parent responses were less complete, our findings may have underestimated the prevalence of behaviour problems in this selected sample. Further research is required with larger samples of children rated as having pervasive hyperactivity and impairment, particularly when this study found higher rates of probable ADHD than previously reported in a community sample.

\section{IMPLICATIONS}

The concern that being overweight in childhood may lead to obesity in adult life has largely overlooked the role that other risk factors may play. Our findings add to previous research by highlighting that children with both barriers to physical activity and risk factors for obesity have increased difficulties with behaviour, particularly hyperactivity/inattention. This suggests that it is important to address the sedentary lifestyle that appears to be increasing in childhood. Although the findings have small effect sizes and cannot determine whether hyperactivity/inattention causes increased risk factors for obesity or vice versa, it is important to recognise the potential moderating influence of hyperactivity/inattention for interventions which aim to promote physical activity in children at risk of obesity and to accommodate for children with problems of hyperactivity/inattention. Additional research should attempt to further assess the influence of risk factors for adult obesity and barriers to physical activity alongside hyperactivity/ inattention in childhood. Specifically, researchers should explore whether interventions to reduce risk factors for obesity could also reduce symptoms of hyperactivity/ inattention, particularly as we found high levels that may indicate probable disorder.

Acknowledgements We would like to thank all the children, parents and teachers who participated in this research. We would like to thank Luke Hogarth and Dr Nivette Mullan for their help with data collection. The rest of the Steps to Active Kids (STAK) study research team was also acknowledged (Professor lan MacDonald, Professor Alan Smyth, Professor Min Yang, Dr Boliang Guo, Professor Chris Hollis, Dr Martin Batty and Dr Dilip Nathan).
Contributors CG designed the trial and data collection tools and monitored data collection for the whole trial. She is the guarantor. LM monitored data collection for the whole trial. CG, KS and LM wrote the statistical analysis plan, LM cleaned and analysed the data and drafted and revised the draft paper. CG and KS revised the paper. All authors read and approved the final manuscript.

Funding This study was funded by the National Institute for Health Research (NIHR), Collaborations for Leadership in Applied Health Research and Care-Nottinghamshire, Derbyshire, Lincolnshire (CLAHRC-NDL).

Competing interests None.

Ethics approval University of Nottingham, Medical School Ethics.

Provenance and peer review Not commissioned; externally peer reviewed.

Data sharing statement No additional data are available.

\section{REFERENCES}

1. Dwyer T, Magnussen CG, Schmidt MD, et al. Decline in physical fitness from childhood to adulthood associated with increased obesity and insulin resistance in adults. Diabetes Care 2009;32:683-7.

2. Thorp AA, Owen N, Neuhaus M, et al. Sedentary behaviors and subsequent health outcomes in adults: a systematic review of longitudinal studies, 1996-2011. Am J Prev Med 2011;41:207-15.

3. Magarey AM, Daniels LA, Boulton TJ, et al. Predicting obesity in early adulthood from childhood and parental obesity. Int $J$ Obes Relat Metab Disord 2003;27:505-13.

4. Janssen I, Katzmarzyk PT, Srinivasan SR, et al. Utility of childhood $\mathrm{BMI}$ in the prediction of adulthood disease: comparison of national and international references. Obesity Res 2005;13:1106-15.

5. Juonala M, Viikari JS, Raitakari OT. Main findings from the prospective cardiovascular risk in young Finns study. Curr Opin Lipidol 2013;24:57-64.

6. Glazebrook C, McPherson AC, Macdonald IA, et al. Asthma as a barrier to children's physical activity: implications for body mass index and mental health. Pediatrics 2006;118:2443-9.

7. Polanczyk G, de Lima MS, Horta BL, et al. The worldwide prevalence of ADHD: a systematic review and metaregression analysis. Am J Psychiatry 2007;164:942-8.

8. Sayal K, Owen V, White K, et al. Impact of early school-based screening and intervention programs for ADHD on children's outcomes and access to services: follow-up of a school-based trial at age 10 years. Arch Pediatr Adolesc Med 2010;164:462-9.

9. Cortese $\mathrm{S}$, Angriman M, Maffeis $\mathrm{C}$, et al. Attention-deficit/ hyperactivity disorder (ADHD) and obesity: a systematic review of the literature. Crit Rev Food Sci Nutr 2008;48:524-37.

10. Holtkamp K, Konrad K, Müller B, et al. Overweight and obesity in children with attention-deficit/hyperactivity disorder. Int J Obes Relat Metab Disord 2004;28:685-9.

11. Erermis S, Cetin N, Tamar M, et al. Is obesity a risk factor for psychopathology among adolescents? Pediatr Int 2004;46:296-301.

12. Curtin C, Bandini LG, Perrin EC, et al. Prevalence of overweight in children and adolescents with attention deficit hyperactivity disorder and autism spectrum disorders: a chart review. BMC Pediatr 2005;5.

13. Waring ME, Lapane KL. Overweight in children and adolescents in relation to attention-deficit/hyperactivity disorder: results from a national sample. Pediatrics 2008;122:e1-6.

14. Chen AY, Kim SE, Houtrow AJ, et al. Prevalence of obesity among children with chronic conditions. Obesity 2010;18:210-13.

15. Bandini LG, Curtin C, Hamad C, et al. Prevalence of overweight in children with developmental disorders in the continuous national health and nutrition examination survey (NHANES) 1999-2002. J Pediatr 2005;146:738-43.

16. Rojo L, Ruiz E, Domínguez JA, et al. Comorbidity between obesity and attention deficit/hyperactivity disorder: population study with 13-15-year-olds. Int J Eat Disord 2006;39:519-22.

17. Egmond-Frölich AW, Widhalm K, de Zwaan M. Association of symptoms of attention-deficit/hyperactivity disorder with childhood overweight adjusted for confounding parental variables. Int $J$ Obes 2012;36:963-68.

18. Harpin VA. The effect of ADHD on the life of an individual, their family, and community from preschool to adult life. Arch Dis Child 2005;90:i2-7.

19. Hoza B. Peer functioning in children with ADHD. Ambul Pediatr 2007;7:101-6.

20. Tiffin PA, Arnott B, Moore HJ, et al. Modelling the relationship between obesity and mental health in children and adolescents: 
findings from the health survey for England 2007. Child Adolesc Psychiatry Ment Health 2011;5:31-42.

21. Pitrou I, Shojaei T, Wazana A, et al. Child overweight, associated psychopathology, and social functioning: a French school-based survey in 6-to 11-year-old children. Obesity 2010;18:809-17.

22. Kim J, Mutyala B, Agiovlasitis S, et al. Health behaviors and obesity among US children with attention deficit hyperactivity disorder by gender and medication use. Prev Med 2011;52:218-22.

23. Lawlor DA, Mamun AA, O'Callaghan MJ, et al. Is being overweight associated with behavioural problems in childhood and adolescence? Findings from the Mater-University study of pregnancy and its outcomes. Arch Dis Child 2005;90:692-7.

24. Griffiths LJ, Dezateux C, Hill A. Is obesity associated with emotional and behavioural problems in children? Findings from the Millenium Cohort Study. Int J Pediatr Obes 2011;6:e423-32.

25. Davis CL, Cooper S. Fitness, fatness, cognition, behavior, and academic achievement among overweight children: do cross-sectional associations correspond to exercise trial outcomes? Prev Med 2011;52:S65-9.

26. Demetriou Y, Höner O. Physical activity interventions in the school setting: a systematic review. Psychol Sport Exerc 2012;13:186-96.

27. Glazebrook C, Batty MJ, Mullan N, et al. Evaluating the effectiveness of a schools-based programme to promote exercise self-efficacy in children and young people with risk factors for obesity: steps to active kids (STAK). BMC Public Health 2011;11:830-6.

28. Hay JA. Adequacy in and predilection for physical activity in children. Clin J Sport Med 1992;2:192-201.

29. Hamill P, Drizd TA, Johnson CL, et al. Physical growth: National Center for Health Statistics percentiles. Am J Clin Nutr 1979;32:607-29.

30. Truby H, Paxton SJ. Development of the children's body image scale. Br J Clin Psychol 2002;41:185-203.

31. Goodman R. Psychometric properties of the strengths and difficulties questionnaire. J Am Acad Child Adolesc Psychiatry 2001;40:1337-45.

32. Goodman R, Ford T, Simmons $\mathrm{H}$, et al. Using the strengths and difficulties questionnaire (SDQ) to screen for child psychiatric disorders in a community sample. Br J Psychiatry 2000;177:534-9.

33. Sayal K, Hornsey $\mathrm{H}$, Warren $\mathrm{S}$, et al. Identification of children at risk of attention deficit/hyperactivity disorder. Soc Psychiatry Psychiatr Epidemiol 2006;41:806-13.

34. Goodman R, Ford T, Richards $\mathrm{H}$, et al. The development and well-being assessment: description and initial validation of an integrated assessment of child and adolescent psychopathology. J Child Psychol Psychiatry 2000;41:645-55.

35. Becker A, Woerner W, Hasselhorn M, et al. Validation of the parent and teacher SDQ in a clinical sample. Eur Child Adolesc Psychiatry 2004:13:ii11-16.
36. Wright CM, Booth IW, Buckler JMH, et al. Growth reference charts for use in the United Kingdom. Arch Dis Child 2002;86:11-14.

37. Cairney J, Hay JA, Faught BE, et al. Generalized self-efficacy and performance on the 20-metre shuttle run in children. Am J Hum Biol 2008;20:132-8

38. Cairney J, Hay JA, Faught BE, et al. Developmental coordination disorder, generalized self-efficacy toward physical activity, and participation in organized and free play activities. J Pediatr 2005; $147: 515-20$.

39. Sallis J, Buono MJ, Roby JJ, et al. Seven-day recall and other physical activity self-reports in children and adolescents. Med Sci Sports Exerc 1993;25:99-108.

40. Meltzer $\mathrm{H}$, Gatward R, Goodman R, et al. The mental health of children and adolescents in Great Britain. London: The Stationery Office, 2000.

41. Sayal K, Goodman R, Ford T. Barriers to the identification of children with attention deficit/hyperactivity disorder. J Child Psychol Psychiatry 2006;47:744-50.

42. Drukker M, Wojciechowski F, Feron FJM, et al. A community study of psychosocial functioning and weight in young children and adolescents. Int J Pediatr Obes 2009;4:91-7.

43. Dubnov-Raz G, Perry A, Berger I. Body mass index of children with attention-deficit/hyperactivity disorder. J Child Neurol 2011;26:302-8.

44. Ebenegger V, Marques-Vidal PM, Munsch S, et al. Relationship of hyperactivity/inattention with adiposity and lifestyle characteristics in preschool children. J Child Neurol 2012;27:852-8.

45. Gentile DA, Swing EL, Lim CG, et al. Video game playing, attention problems, and impulsiveness: evidence of bidirectional causality. Psychol Popular Media Cult 2012;1:62-70.

46. Swing EL, Gentile DA, Anderson CA, et al. Television and video game exposure and the development of attention problems. Pediatrics 2010;126:214-21.

47. Miller CJ, Marks DJ, Miller SR, et al. Brief report: television viewing and risk for attention problems in preschool children. $J$ Pediatr Psychol 2007;32:448-52.

48. Basterfield L, Adamson AJ, Frary JK, et al. Longitudinal study of physical activity and sedentary behavior in children. Pediatrics 2011;127:e24-30.

49. Baerg S, Cairney J, Hay J, et al. Evaluating physical activity using accelerometry in children at risk of developmental coordination disorder in the presence of attention deficit hyperactivity disorder. Res Dev Disabil 2011;32:1343-50.

50. National Child Measurement Programme: England 2011/12 school year. The Health and Social Care Information Centre, Lifestyle Statistics, 2012. 